\title{
Pharmacokinetic results of a phase I trial of sorafenib in combination with dacarbazine in patients with advanced solid tumors
}

\author{
Erich Brendel • Matthias Ludwig · Chetan Lathia • \\ Caroline Robert $\cdot$ Stanislas Ropert $\cdot$ \\ Jean-Charles Soria $\cdot$ Jean-Pierre Armand
}

Received: 22 February 2010 / Accepted: 11 August 2010 / Published online: 7 September 2010

(C) The Author(s) 2010. This article is published with open access at Springerlink.com

\begin{abstract}
Purpose Sorafenib, a multikinase inhibitor of Raf and several growth factor receptors, is under investigation in combination with dacarbazine, a commonly used chemotherapeutic agent for the treatment of many cancers. The current phase I study investigates the effects of sorafenib on the pharmacokinetic (PK) profile of dacarbazine and its metabolite 5-amino-imidazole-4-carboxamide (AIC). (AIC is formed in amounts equimolar to the active alkylating moiety, methane diazohydroxide, which is undetectable by known validated assays.)

Methods Patients with advanced solid tumors received intravenous dacarbazine $1,000 \mathrm{mg} / \mathrm{m}^{2}$ on day 1 of a 21 -day cycle to evaluate the PK of dacarbazine alone. Sorafenib
\end{abstract}

Electronic supplementary material The online version of this article (doi:10.1007/s00280-010-1423-9) contains supplementary material, which is available to authorized users.

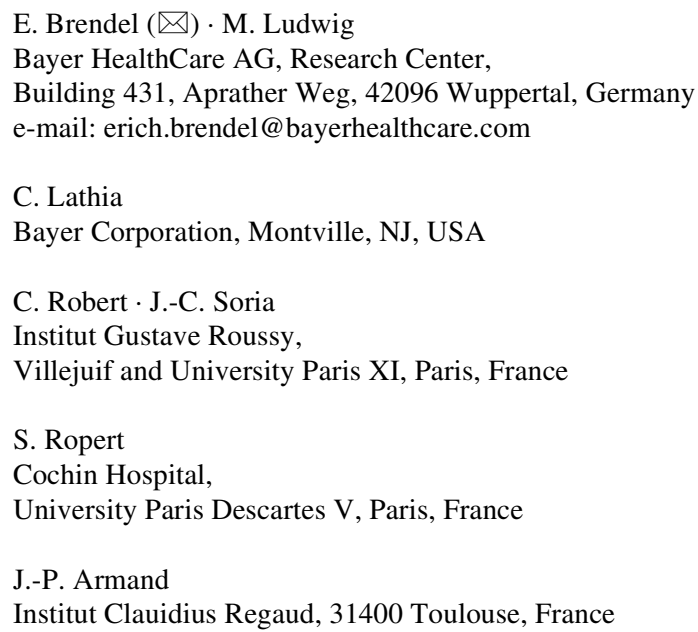

$400 \mathrm{mg}$ was administered twice daily continuously starting at day 2 of cycle 1 . The PK of dacarbazine in the presence of sorafenib was assessed on day 1 of cycle 2 . Sorafenib PK was also assessed at steady state.

Results PK data were available for 15 of 23 patients. With concomitant administration of sorafenib, the mean AUC and $C_{\max }$ values of dacarbazine were reduced by 23 and $16 \%$, respectively. Mean $\mathrm{AUC}$ and $C_{\max }$ values of $\mathrm{AIC}$ were increased by 41 and $45 \%$, respectively, with individual increases of up to 106 and $136 \%$, respectively. The apparent terminal half-lives of the two compounds were not significantly influenced by sorafenib. Based on coefficients of variation, the AUC and $C_{\max }$ values for sorafenib and its three metabolites were highly variable with dacarbazine coadministration.

Conclusions Concomitant administration of sorafenib and dacarbazine as described above may result in decreased dacarbazine exposure but increased AIC exposure.

Keywords Sorafenib - Dacarbazine $\cdot$ AIC . Pharmacokinetics · Phase I

\section{Introduction}

Sorafenib is a multikinase inhibitor of Raf, vascular endothelial growth factor (VEGF) receptors, and plateletderived growth factor receptors $[1,2]$. It has been approved as a single agent by the US Food and Drug Administration (FDA) and the European Medicines Agency (EMA) for the treatment of advanced renal cell carcinoma and unresectable hepatocellular carcinoma. In addition, sorafenib is being tested in combination with other agents in a variety of advanced solid tumors such as melanoma, breast cancer, renal cell carcinoma, hepatic cancer, and non-small-cell 
lung cancer [3-16]. Dacarbazine is the most commonly used FDA- and EMA-approved chemotherapeutic agent for the treatment of advanced melanoma. Dacarbazine is metabolized by various cytochrome P450 (CYP) isoenzymes such as CYP1A2, CYP1A1, and CYP2E1 [17]. Sorafenib is primarily metabolized in the liver by CYP3A4 [18]. Therefore, concomitant sorafenib administration is not expected to affect dacarbazine metabolism, and the likelihood of a pharmacokinetic (PK) drug-drug interaction between sorafenib and dacarbazine is low.

An earlier phase I study estimated that the maximum-tolerated dose of sorafenib in combination with dacarbazine $1,000 \mathrm{mg} / \mathrm{m}^{2}$ was $400 \mathrm{mg}$ twice daily (the standard singleagent doses for each agent) [19]. The primary objective of this study was to evaluate the PK profiles of dacarbazine with and without concomitant sorafenib under steady state conditions. A secondary objective was to determine the steady-state PK profiles of sorafenib and its metabolites BAY 67-3472 (M2), BAY 43-9007 (M4), and BAY 687769 (M5) in the presence of dacarbazine. This paper reports on PK and safety data. A separate manuscript (in preparation) [20] reports on efficacy and functional analysis using dynamic contrast-enhanced ultrasonography (DCE-US) representing the blood volume and microarray analyses of gene expression obtained in sequential tumor biopsies.

\section{Patients and methods}

\section{Patients}

Patients with metastatic, histologically confirmed solid tumors were included in this study. Eligible patients had at least one lesion that could be accurately and serially measured per Response Evaluation Criteria in Solid Tumors (RECIST) guidelines [21], were $\geq 18$ years of age with an Eastern Cooperative Oncology Group (ECOG) performance status of 0 or 1 , had adequate bone marrow, liver, and renal functions, and had a life expectancy of at least 12 weeks. Patients were excluded if they had previous or concurrent cancer that was distinct from the tumor being evaluated in this study, unless the other cancer was curatively treated more than 3 years prior to study entry; clinically evident congestive heart failure; cardiac arrhythmias; active coronary heart disease or ischemia; uncontrolled hypertension; active clinically serious infections; or active brain metastases. Anticancer chemotherapy, immunotherapy, or vaccine therapy was not permitted during or within 30 days prior to the start of study treatment. Prior treatment with inhibitors of Raf, VEGF, or mTOR signaling pathways or farnesyl transferase inhibitors was not permitted.
Study design

This phase I, single-center, open-label, uncontrolled study was conducted in France between September 2005 (date of first patient first visit) and August 2006 (data cutoff date). On day 1 of a 21-day cycle, dacarbazine $1,000 \mathrm{mg} / \mathrm{m}^{2}$ was administered as a 1-h infusion. Sorafenib $400 \mathrm{mg}$ was administered twice daily continuously starting on day 2 of cycle 1. Toxicity-related dose modifications of sorafenib and dacarbazine were performed in accordance with protocol-specified guidelines. Treatment continued until the occurrence of unacceptable toxicity, tumor progression, or death. Sorafenib tablets were supplied by Bayer HealthCare AG (Leverkusen, Germany); dacarbazine was supplied by Faulding Pharmaceuticals SA (Asnieres, France). The study was conducted in accordance with the Declaration of Helsinki, the International Conference on Harmonization Good Clinical Practice guidelines, the EU-Directive 2001/ 20/EC, and local applicable laws. All patients provided signed informed consent before starting study treatment.

\section{Study outcomes}

The primary endpoint was the determination of the PK profile of dacarbazine with and without sorafenib. Secondary endpoints included evaluation of the PK profile of sorafenib in the presence of dacarbazine, safety and efficacy of the combination treatment, novel biomarker analyses using DCE-US, and gene profile analyses. This paper reports on PK and safety data; the other results are reported in a separate manuscript (in preparation) [20].

Pharmacokinetic variables and sampling schedules

Dacarbazine is a prodrug from which the active alkylating moiety methane diazohydroxide is formed by metabolization. In this metabolic process, the inactive metabolite 5-amino-imidazole-4-carboxamide (AIC) is formed in equimolar quantities as methane diazohydroxide, which cannot be analytically measured [17]. Therefore, in addition to the PK of dacarbazine, we also studied the PK of AIC to understand the changes in the exposure of the active alkylating moiety in the presence of sorafenib.

On day 1 of cycle 1 , plasma samples were obtained prior to dacarbazine administration and at $0.5,1.0,1.25$, $1.5,2.0,4.0,8.0,12.0$, and $24.0 \mathrm{~h}$ following dacarbazine administration to assess the PK of dacarbazine and AIC in the absence of sorafenib. On day 1 of cycle 2, samples were collected from the same patients to assess the PK of dacarbazine in the presence of sorafenib at the same time points as above. Additional samples were collected on day 1 of cycle 2 prior to sorafenib dosing and at $0.5,1.0,2.0$, 
Table 1 Patient baseline characteristics

\begin{tabular}{|c|c|c|c|}
\hline \multirow[t]{2}{*}{$\begin{array}{l}\text { Table } 1 \text { Patient baseline } \\
\text { characteristics }\end{array}$} & Characteristics & $\begin{array}{l}\text { Patients included } \\
\text { in the PK analysis }(n=15)\end{array}$ & $\begin{array}{l}\text { Patients included in the } \\
\text { safety analysis }(n=23)\end{array}$ \\
\hline & \multicolumn{3}{|l|}{ Sex, $n(\%)$} \\
\hline & Male & $10(67)$ & $11(48)$ \\
\hline & Female & $5(33)$ & $12(52)$ \\
\hline & Age at enrollment, mean $\pm \mathrm{SD}^{\mathrm{a}}$ (year) & $59.3 \pm 7.5$ & $57.2 \pm 8.9$ \\
\hline & \multicolumn{3}{|l|}{ Primary cancer type, $n(\%)$} \\
\hline & Malignant melanoma & $4(27)$ & $4(17)$ \\
\hline & Leiomyosarcoma & $3(20)$ & $4(17)$ \\
\hline & Adenocarcinoma & $2(13)$ & $5(22)$ \\
\hline & Neuroendocrine carcinoma & $2(13)$ & $2(9)$ \\
\hline & Carcinoid tumor & $1(7)$ & $1(4)$ \\
\hline & Epithelioid mesothelioma & $1(7)$ & $3(13)$ \\
\hline & Hemangiopericytoma & $1(7)$ & $1(4)$ \\
\hline & Hepatocarcinoma & $1(7)$ & $1(4)$ \\
\hline & Nesidioblastoma & 0 & $1(4)$ \\
\hline & Sarcoma & 0 & $1(4)$ \\
\hline & \multicolumn{3}{|l|}{$\mathrm{AJCC}^{\mathrm{b}}$ stage at study entry, $n(\%)$} \\
\hline & Stage IV & $14(93)$ & $22(96)$ \\
\hline & Unknown & $1(7)$ & $1(4)$ \\
\hline & \multicolumn{3}{|l|}{ ECOG performance status, $n(\%)$} \\
\hline & 0 & $6(40)$ & $10(44)$ \\
\hline & 1 & $8(53)$ & $12(52)$ \\
\hline & Missing & $1(7)$ & $1(4)$ \\
\hline & \multicolumn{3}{|l|}{ Prior anticancer therapy, $n(\%)$} \\
\hline & \multicolumn{3}{|l|}{ Systemic adjuvant therapy } \\
\hline & Antineoplastic agents & $3(20)$ & $5(22)$ \\
\hline & Immunostimulants & $1(7)$ & $1(4)$ \\
\hline & \multicolumn{3}{|l|}{ Systemic palliative therapy } \\
\hline & Antineoplastic agents & $11(73)$ & $19(83)$ \\
\hline & Endocrine therapy & $1(7)$ & $3(13)$ \\
\hline & Other & $1(7)$ & $2(9)$ \\
\hline & Radiotherapy & $6(40)$ & $10(43)$ \\
\hline & \multicolumn{3}{|l|}{ Prior anticancer regimens, $n(\%)$} \\
\hline & 0 & $1(7)$ & $1(4)$ \\
\hline & 1 & $7(47)$ & $10(44)$ \\
\hline & $\geq 2$ & $7(47)$ & $12(52)$ \\
\hline & \multicolumn{3}{|c|}{ Time since initial diagnosis, mean $\pm \mathrm{SD}^{\mathrm{a}}$ (week) } \\
\hline${ }^{\mathrm{a}}$ Standard deviation & Malignant melanoma & $141.2 \pm 145.0$ & $141.2 \pm 145.0$ \\
\hline b American Joint Committee on & Other tumor types & $245.4 \pm 331.7$ & $197.9 \pm 261.3$ \\
\hline
\end{tabular}

${ }^{a}$ Standard deviation

b American Joint Committee on Cancer
4.0, 8.0, 10.0, and $12.0 \mathrm{~h}$ thereafter to evaluate the PK profile of sorafenib and its main metabolites, M2, M4, and $\mathrm{M} 5$, in the presence of dacarbazine. Samples for dacarbazine measurements were stored at or below $-70^{\circ} \mathrm{C}$; samples for sorafenib measurements were stored below $-15^{\circ} \mathrm{C}$. Stability data indicated that all analytes were stable during analysis.

The following PK variables were determined for dacarbazine and AIC on day 1 of cycle 1 and day 1 of cycle 2 : area under the plasma concentration-time curve (AUC) from zero to infinity after a single dose [AUC(0-inf)], AUC from time zero to the last data point [AUC(0-tn)], maximum concentration of drug in plasma $\left(C_{\text {max }}\right)$, time to reach maximum drug concentration in plasma $\left(t_{\max }\right)$, and apparent terminal half-life $\left(t_{1 / 2}\right)$. The following variables were determined for sorafenib, M2, M4, and M5 on day 1 of cycle 2: AUC from time $0-12 \mathrm{~h}$ after dose at steady state [AUC $\left.(0-12)_{\mathrm{ss}}\right], \mathrm{AUC}(0-12)_{\mathrm{ss}}$ normalized with respect to 
Fig. 1 a Plasma concentrations (geometric means/geometric standard deviation) of dacarbazine after a 1-h intravenous infusion of $1,000 \mathrm{mg} / \mathrm{m}^{2}$ dacarbazine without (cycle 1) or with (cycle 2) concomitant multiple oral doses of $400 \mathrm{mg}$ bid sorafenib $(n=15)$ b Plasma concentrations (geometric means/ geometric standard deviation) of AIC after a 1-h intravenous infusion of $1,000 \mathrm{mg} / \mathrm{m}^{2}$ dacarbazine without (cycle 1) or with (cycle 2) concomitant multiple oral doses of $400 \mathrm{mg}$ bid sorafenib $(n=15)$ c Plasma concentrations (geometric means/ geometric standard deviation) of sorafenib after multiple oral doses of $400 \mathrm{mg}$ bid sorafenib and following a concomitant 1-h intravenous infusion of $1,000 \mathrm{mg} / \mathrm{m}^{2}$ dacarbazine on day 1 of cycle $2(n=15)$
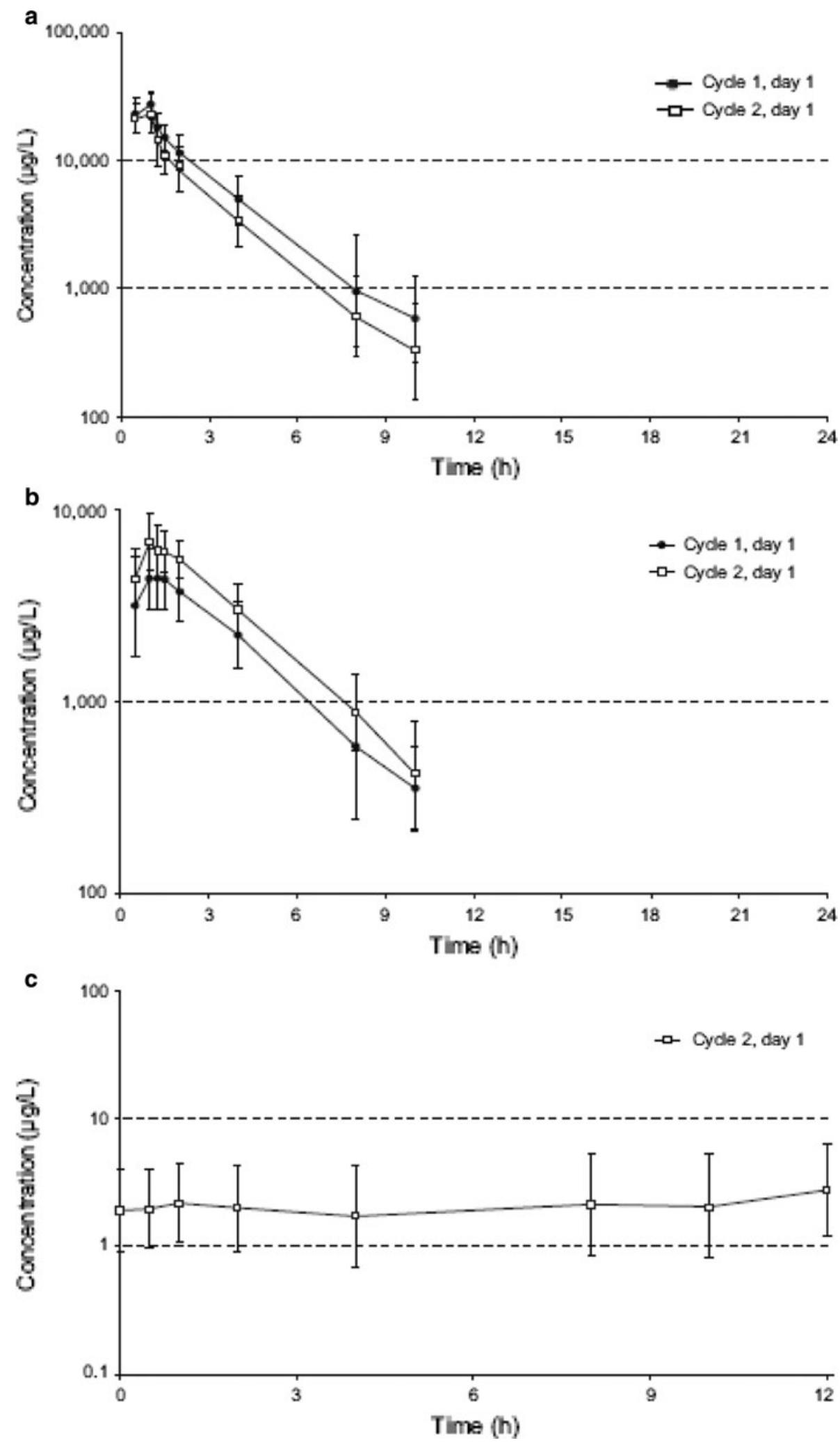

dose (in $\mathrm{mg}$ ) per $\mathrm{kg}$ body weight $\left[\mathrm{AUC}(0-12)_{\mathrm{ss}, \mathrm{norm}}\right], C_{\max }$ at steady state $\left(C_{\max , s s}\right), C_{\max , s s}$ normalized with respect to dose (in $\mathrm{mg}$ ) per $\mathrm{kg}$ body weight $\left(C_{\max , \text { ss,norm }}\right)$, and $t_{\max }$ at steady state $\left(t_{\max , s s}\right)$.
Pharmacokinetic assay methods and analyses

All analytes in plasma samples were quantified using a fully validated liquid chromatography-tandem mass 
Table 2 PK data for dacarbazine and AIC after a 1-h intravenous infusion of 1,000 mg/m $\mathrm{m}^{2}$ dacarbazine without (day 1, cycle 1) or with (day 2 , cycle 2) administration of concomitant multiple oral doses of $400 \mathrm{mg}$ bid sorafenib $(n=15)$

\begin{tabular}{|c|c|c|c|c|c|c|}
\hline \multirow[t]{2}{*}{ Parameters } & \multicolumn{3}{|c|}{ Dacarbazine } & \multicolumn{3}{|l|}{ AIC } \\
\hline & Cycle 1 & Cycle 2 & Cycle 2/cycle 1 & Cycle 1 & Cycle 2 & Cycle 2/cycle 1 \\
\hline \multicolumn{7}{|c|}{$\operatorname{AUC}(0-i n f)(m g ~ h / l)$} \\
\hline $\mathrm{GM}^{\mathrm{a}}\left(\% \mathrm{CV}^{\mathrm{b}}\right)$ & $65.0(31)$ & $50.0(36)$ & & $20.6(35)$ & $28.9(26)$ & \\
\hline Range & $29.4-111.5$ & $24.5-87.8$ & & $11.3-33.2$ & $21.8-56.0$ & \\
\hline Ratio $\left(90 \% \mathrm{CI}^{\mathrm{c}}\right.$ & & & $0.769(0.629-0.941)$ & & & $1.408(1.167-1.699)$ \\
\hline \multicolumn{7}{|c|}{$\operatorname{AUC}(0-\mathrm{tn})(\mathrm{mg} \mathrm{h} / \mathrm{l})$} \\
\hline $\mathrm{GM}^{\mathrm{a}}\left(\% \mathrm{CV}^{\mathrm{b}}\right)$ & $62.9(29)$ & $49.0(35)$ & & $19.1(35)$ & $27.1(25)$ & \\
\hline Range & $29.0-105.3$ & $23.8-84.3$ & & $10.5-29.7$ & $19.8-50.4$ & \\
\hline \multicolumn{7}{|l|}{$C_{\max }(\mathrm{mg} / \mathrm{l})$} \\
\hline $\mathrm{GM}^{\mathrm{a}}\left(\% \mathrm{CV}^{\mathrm{b}}\right)$ & $28.9(26)$ & $24.4(26)$ & & $4.96(39)$ & $7.16(26)$ & \\
\hline Range & $14.4-45.3$ & $13.6-35.8$ & & $2.30-9.29$ & $4.18-10.20$ & \\
\hline Ratio $\left(90 \% \mathrm{CI}^{\mathrm{c}}\right.$ & & & $0.843(0.718-0.990)$ & & & $1.445(1.184-1.765)$ \\
\hline \multicolumn{7}{|l|}{$t_{1 / 2}(\mathrm{~h})$} \\
\hline $\mathrm{GM}^{\mathrm{a}}\left(\% \mathrm{CV}^{\mathrm{b}}\right)$ & $1.87(29)$ & $1.72(22)$ & & $2.27(27)$ & $2.17(26)$ & \\
\hline Range & $1.34-3.76$ & $1.31-2.87$ & & $1.30-3.73$ & $1.50-3.21$ & \\
\hline \multicolumn{7}{|l|}{$t_{\max }(\mathrm{h})$} \\
\hline Median & 1.00 & 1.00 & & 1.17 & 1.17 & \\
\hline Range & $0.50-1.08$ & $0.50-1.17$ & & $0.50-1.58$ & $1.00-2.00$ & \\
\hline $\begin{array}{l}\text { a } \text { Geometric mea } \\
{ }^{b} \text { Coefficient of } v \\
{ }^{c} \text { Confidence inte }\end{array}$ & & & & & & \\
\hline \multirow{8}{*}{\multicolumn{2}{|c|}{$\begin{array}{l}\text { Table } 3 \text { PK parameters of } \\
\text { sorafenib and its metabolites } \\
\text { BAY-67 } 3472(\mathrm{M} 2) \text {, BAY } 43- \\
9007 \text { (M4), and BAY } 68-7769 \\
\text { (M5) after multiple oral doses of } \\
400 \mathrm{mg} \text { bid sorafenib and fol- } \\
\text { lowing a concomitant } 1-\mathrm{h} \mathrm{intra-} \\
\text { venous infusion of } 1,000 \mathrm{mg} / \mathrm{m}^{2} \\
\text { dacarbazine on day } 1 \text { of cycle } 2\end{array}$}} & Parameters & Sorafenib $(n=15)^{\mathrm{a}}$ & $\mathrm{M} 2(n=15)^{\mathrm{a}}$ & $\mathrm{M} 4(n=15)^{\mathrm{b}}$ & M5 $(n=13)^{\mathrm{c}}$ \\
\hline & & $\operatorname{AUC}(0-12)_{\mathrm{ss}}(\mathrm{mg}$ & & & & \\
\hline & & $\mathrm{GM}^{\mathrm{d}}\left(\% \mathrm{CV}^{\mathrm{e}}\right)$ & $28.3(84)$ & $3.01(207)$ & $1.46(202)$ & $1.17(225)$ \\
\hline & & Range & $6.13-85.7$ & $0.195-17.6$ & $0.176-14.0$ & $0.218-9.31$ \\
\hline & & $\operatorname{AUC}(0-12)_{\mathrm{ss}, \text { norm }}$ & h/l) & & & \\
\hline & & $\mathrm{GM}^{\mathrm{d}}\left(\% \mathrm{CV}^{\mathrm{e}}\right)$ & $4.75(93)$ & $0.489(228)$ & $0.254(207)$ & $0.200(238)$ \\
\hline & & Range & $0.934-16.1$ & $0.029-3.15$ & $0.026-2.23$ & $0.024-1.44$ \\
\hline & & $C_{\max , \mathrm{ss}}(\mathrm{mg} / \mathrm{l})$ & & & & \\
\hline \multirow{2}{*}{\multicolumn{2}{|c|}{$\begin{array}{l}n=14 \text { for } \operatorname{AUC}(0-12)_{\mathrm{ss}} \text { and } \\
\operatorname{AUC}(0-12)_{\mathrm{ss}, \text { norm }}\end{array}$}} & $\mathrm{GM}^{\mathrm{d}}\left(\% \mathrm{CV}^{\mathrm{e}}\right)$ & 3.67 (77) & $0.371(197)$ & $0.149(237)$ & $0.137(225)$ \\
\hline & & Range & $0.905-9.66$ & $0.035-2.03$ & $0.016-1.48$ & $0.022-0.943$ \\
\hline \multicolumn{2}{|c|}{ b $n=13$ for AUC $(0-12)_{\mathrm{ss}}$ and } & $C_{\max , \mathrm{ss}, \mathrm{norm}}(\mathrm{kg} / \mathrm{l})$ & & & & \\
\hline \multirow{2}{*}{\multicolumn{2}{|c|}{$\begin{array}{l}\operatorname{AUC}(0-12)_{\mathrm{ss}, \text { norm }} \\
{ }^{c} n=12 \text { for } \operatorname{AUC}(0-12)_{\mathrm{ss}} \text { and } \\
\operatorname{AUC}(0-12)_{\mathrm{ss}, \text { norm }}\end{array}$}} & $\mathrm{GM}^{\mathrm{d}}\left(\% \mathrm{CV}^{\mathrm{e}}\right)$ & $0.620(84)$ & $0.061(211)$ & $0.026(244)$ & $0.023(245)$ \\
\hline & & Range & $0.155-1.81$ & $0.005-0.367$ & $0.003-0.236$ & $0.002-0.146$ \\
\hline \multicolumn{2}{|c|}{ d Geometric mean } & $t_{\max , \mathrm{ss}}(\mathrm{h})$ & & & & \\
\hline \multicolumn{2}{|c|}{ e Coefficient of variation } & Median (range) & $8.3(0.5-12.0)$ & $4.0(0-12.0)$ & $8.3(0.5-12.0)$ & $4.0(0-12.0)$ \\
\hline
\end{tabular}

spectrometry assay method with a lower limit of quantification of $40.6 \mu \mathrm{g} / 1$ for dacarbazine, $40.7 \mu \mathrm{g} / \mathrm{l}$ for $\mathrm{AIC}$, and $0.01 \mathrm{mg} / \mathrm{l}$ for sorafenib and its metabolites. The assay for each sample set was performed once. Mean inter-assay precision ranges as determined by analysis of quality control samples were $7.0-8.7 \%$ for dacarbazine, $2.8-9.3 \%$ for AIC, $1.5-12.4 \%$ for sorafenib, $2.6-4.5 \%$ for $\mathrm{M} 2$, 3.9-5.2\% for M4, and 3.2-6.7\% for M5. Corresponding mean inter-assay accuracy ranges were 97.1-104.7\% for dacarbazine, 99.3-105.3\% for AIC, 102.3-107.0\% for sorafenib, 97.9-103.2\% for M2, 98.1-100.3\% for M4, and 95.5-101.0\% for M5. The parameters $\mathrm{AUC}$, $\mathrm{AUC}(0-\mathrm{tn})$, and $C_{\max }$ of dacarbazine and AIC were analyzed after logarithmic transformations applying an analysis of variance assuming a log-normal distribution. 
Safety

Safety was evaluated in all patients who had received at least one dose of either study treatment. Safety was assessed through observed adverse events (AEs) and results of physical examination, laboratory tests, and vital signs measurement. Safety assessment took place at baseline and weekly starting from day 1 of cycle 1 . AEs were coded and graded using version 3.0 of the National Cancer Institute Common Toxicity Criteria.

\section{Determination of sample size}

As this was a descriptive PK and safety phase I study, no formal sample size estimation was performed. The planned enrollment of approximately 25 patients was based on the requirements of relevant PK data sampling in a phase I trial.

\section{Results}

The study enrolled 24 patients, one of whom developed progressive disease before study treatment. The remaining 23 patients underwent treatment and were evaluable for safety analysis. Twenty-one patients (91\%) discontinued treatment owing to progressive disease and two patients (9\%) discontinued owing to AEs. Complete PK data were available for 15 patients. The other 8 patients had incomplete or no PK data on sorafenib and/or dacarbazine and were not included in the PK evaluation. The baseline characteristics of patients are reported in Table 1. Detailed dosing and drug exposure data are reported in the supplementary table.

\section{Pharmacokinetics}

The 15 patients included in the PK analysis did not undergo any dose modifications during the PK evaluation period. For 13 of the 15 patients, the PK profile of dacarbazine was determined on day 1 of cycle 1 in the absence of sorafenib and repeated on day 1 of cycle 2 following a 20-day treatment period of sorafenib, as planned. For two patients, the second dacarbazine PK sampling was done on day 1 of cycle 3 and day 1 of cycle 6 . For all the PK analyses, these were combined with data obtained from other patients on day 1 of cycle 2 . Sorafenib PK sampling was performed in all patients during the second dacarbazine PK sampling.

Geometric mean plasma concentration-time data for dacarbazine, AIC, and sorafenib are shown in Fig. 1a-c, respectively. While plasma concentrations of dacarbazine were slightly lower in cycle 2 at $4 \mathrm{~h}$ after start of infusion and following times when compared with those in cycle 1 , the corresponding mean plasma concentrations of AIC were distinctly higher in cycle 2 compared with cycle 1 . The apparent $t_{1 / 2}$ of either dacarbazine or AIC was not altered on concomitant administration of sorafenib. Mean plasma concentrations of sorafenib ranged between 1.7 and $3.0 \mathrm{mg} / \mathrm{l}$.

Table 2 summarizes the PK results for dacarbazine and AIC. While the mean AUC and $C_{\max }$ of dacarbazine were reduced by 23 and $16 \%$, respectively, mean AUC and $C_{\max }$ of AIC were increased by 41 and $45 \%$, respectively, with individual increases of up to 106 and $136 \%$, respectively. The apparent $t_{1 / 2}$ of either compound was not significantly influenced by concomitant administration of sorafenib. Table 3 reports the steady state PK data for sorafenib and its metabolites. Sorafenib contributes approximately $83 \%$ to the sum of $\operatorname{AUC}(0-12)_{\mathrm{ss}}$ values, while the metabolites contribute approximately 9\% (M2), 4\% (M4), and 3\% (M5). From the values of the coefficients of variation, it is

Table 4 Incidence of drug-related treatment-emergent AEs associated with dacarbazine, sorafenib, or both, and affecting at least two patients

\begin{tabular}{|c|c|c|c|}
\hline & \multicolumn{3}{|c|}{ Total incidence, $n(\%)(n=23)$} \\
\hline & All grades & Grade $3^{\mathrm{a}}$ & Grade $4^{\mathrm{a}}$ \\
\hline \multicolumn{4}{|l|}{ Blood/bone marrow } \\
\hline Hemoglobin & $5(22)$ & $5(22)$ & 0 \\
\hline Lymphopenia & $2(9)$ & $2(9)$ & 0 \\
\hline Neutrophils & $5(22)$ & $3(13)$ & $2(9)$ \\
\hline Platelets & $7(30)$ & $1(4)$ & $4(17)$ \\
\hline \multicolumn{4}{|l|}{ Constitutional symptoms } \\
\hline Fatigue & $17(74)$ & $4(17)$ & 0 \\
\hline Fever & $7(30)$ & 0 & 0 \\
\hline Weight loss & $2(9)$ & 0 & 0 \\
\hline \multicolumn{4}{|l|}{ Dermatology/skin } \\
\hline Alopecia & $8(35)$ & 0 & 0 \\
\hline Hand-foot skin reaction & $11(48)$ & $1(4)$ & 0 \\
\hline Pruritus & $5(22)$ & 0 & 0 \\
\hline Rash/desquamation & $11(48)$ & $2(9)$ & 0 \\
\hline \multicolumn{4}{|l|}{ Gastrointestinal } \\
\hline Anorexia & $11(48)$ & $1(4)$ & 0 \\
\hline Constipation & $3(13)$ & 0 & 0 \\
\hline Diarrhea & $11(48)$ & 0 & 0 \\
\hline Mucositis (symptomatic) & $2(9)$ & 0 & 0 \\
\hline Nausea & $15(65)$ & $1(4)$ & 0 \\
\hline Taste alteration & $2(9)$ & 0 & 0 \\
\hline Vomiting & $10(44)$ & $2(9)$ & 0 \\
\hline \multicolumn{4}{|l|}{ Metabolic/laboratory } \\
\hline Amylase & $4(17)$ & $4(17)$ & 0 \\
\hline Lipase & $5(22)$ & $2(9)$ & $3(13)$ \\
\hline \multicolumn{4}{|l|}{ Pain } \\
\hline Headache & $2(8)$ & 0 & 0 \\
\hline
\end{tabular}

\footnotetext{
a Worst grade
} 
Table 5 Individual patient parameters of AIC after a 1-h infusion of $1,000 \mathrm{mg} / \mathrm{m}^{2}$ dacarbazine without (cycle 1) or with (cycle 2) concomitant administration of multiple oral doses of $400 \mathrm{mg}$ sorafenib bid and percent changes in hematologic parameters in patients valid for PK analysis $(n=15)$

\begin{tabular}{|c|c|c|c|c|c|c|c|}
\hline \multirow[t]{2}{*}{ Reference \# } & \multicolumn{2}{|l|}{$C_{\max }(\mathrm{mg} / \mathrm{l})$} & \multicolumn{2}{|c|}{$\operatorname{AUC}(0-$ inf $)(\mathrm{mg} \mathrm{h} / \mathrm{l})$} & \multicolumn{3}{|c|}{$\begin{array}{l}\text { Percent change from baseline } \\
\text { (NCI CTCAE v } 3.0^{\mathrm{a}} \text { grade) }\end{array}$} \\
\hline & $\mathrm{C} 1 ; \mathrm{C} 2$ & $\mathrm{C} 2 / \mathrm{C} 1$ & $\mathrm{C} 1 ; \mathrm{C} 2$ & $\mathrm{C} 2 / \mathrm{C} 1$ & Platelets & Leukocytes & Neutrophils \\
\hline 01 & $4.23 ; 7.22^{\mathrm{a}}$ & 1.70 & $14.5 ; 27.2^{\mathrm{b}}$ & 1.87 & $-89.3(\mathrm{G} 4)$ & $-70.4(\mathrm{G} 3)$ & $-74.9(\mathrm{G} 3)$ \\
\hline 03 & $9.29 ; 10.23$ & 1.10 & $30.9 ; 33.9$ & 1.10 & $-41.1(\mathrm{G} 1)$ & $-44.9(\mathrm{G} 1)$ & -57.0 \\
\hline 05 & $6.36 ; 7.44$ & 1.17 & $23.7 ; 27.3$ & 1.15 & $-72.8(\mathrm{G} 1)$ & $-75.2(\mathrm{G} 2)$ & $-81.2(\mathrm{G} 2)$ \\
\hline 06 & $2.30 ; 5.43$ & 2.36 & $11.3 ; 23.4$ & 2.06 & $-96.6(\mathrm{G} 4)$ & $-94.9(\mathrm{G} 4)$ & $-97.2(\mathrm{G} 4)$ \\
\hline 07 & $3.21 ; 4.18$ & 1.30 & $15.2 ; 26.0$ & 1.71 & $-24.7(\mathrm{G} 1)$ & $-36.8(\mathrm{G} 1)$ & -46.5 \\
\hline 09 & $3.94 ; 7.77$ & 1.97 & $16.2 ; 31.0$ & 1.92 & $-24.4(\mathrm{G} 1)$ & -35.8 & -37.0 \\
\hline 11 & $3.87 ; 6.76$ & 1.75 & $13.5 ; 21.9$ & 1.62 & $-88.9(\mathrm{G} 4)$ & $-63.7(\mathrm{G} 2)$ & $-80.0(\mathrm{G} 3)$ \\
\hline 12 & $6.05 ; 8.67$ & 1.43 & $29.0 ; 39.8$ & 1.37 & $-71.3(\mathrm{G} 1)$ & $-72.1(\mathrm{G} 3)$ & $-83.7(\mathrm{G} 3)$ \\
\hline 13 & $5.48 ; 5.89$ & 1.08 & $21.8 ; 28.7$ & 1.31 & $-73.3(\mathrm{G} 2)$ & $-74.0(\mathrm{G} 3)$ & $-85.4(\mathrm{G} 3)$ \\
\hline 14 & $5.32 ; 9.78$ & 1.84 & $33.2 ; 56.0$ & 1.68 & $-95.0(\mathrm{G} 4)$ & $-90.5(\mathrm{G} 4)$ & $-98.3(\mathrm{G} 4)$ \\
\hline 15 & $7.55 ; 9.54$ & 1.26 & $27.2 ; 32.7$ & 1.20 & $-50.4(\mathrm{G} 1)$ & $-55.4(\mathrm{G} 2)$ & $-55.6(\mathrm{G} 2)$ \\
\hline 17 & $5.40 ; 6.84$ & 1.27 & $21.4 ; 24.9$ & 1.16 & $-52.9(\mathrm{G} 1)$ & -37.9 & -42.6 \\
\hline 22 & $7.88 ; 9.07$ & 1.15 & $24.6 ; 22.5$ & 0.91 & $-85.0(\mathrm{G} 2)$ & $-66.7(\mathrm{G} 3)$ & $-65.8(\mathrm{G} 2)$ \\
\hline 23 & $4.97 ; 6.53$ & 1.32 & $27.8 ; 31.7$ & 1.14 & $-83.2(\mathrm{G} 1)$ & $-70.1(\mathrm{G} 2)$ & $-77.3(\mathrm{G} 1)$ \\
\hline 24 & $3.37 ; 5.29^{c}$ & 1.57 & $14.7 ; 21.8^{\mathrm{b}}$ & 1.49 & -13.7 & -15.9 & -40.6 \\
\hline
\end{tabular}

${ }^{a}$ National Cancer Institute Common Terminology Criteria for Adverse Events version 3.0

b Data from cycle 3

${ }^{c}$ Data from cycle 6

evident that the PK parameters of sorafenib and its metabolites showed a high degree of variability.

Safety

Overall, toxicities were manageable, with the vast majority of grade 3/4 AEs improving or resolving upon transient study drug dose reduction or discontinuation. No patient died of treatment-related causes; 10 patients $(43.5 \%)$ died of progressive disease, 5 within 30 days after the last dose of a study drug and 5 thereafter.

Table 4 summarizes the incidence of treatment-emergent AEs related to one or both of the study drugs and affecting at least two patients. The most common grade 3/4 toxicities included amylase or lipase elevation, which was attributed to sorafenib and asymptomatic in all cases. The hematologic toxicities were attributed to both study drugs. The most common drug-related toxicities of any grade were fatigue, nausea, diarrhea, hand-foot skin reaction, and rash/ desquamation, each affecting a minimum of just under half of the patients. The most common categories of toxicities of any grade were gastrointestinal (19 patients [83\%]), constitutional (18 patients [78\%]), and dermatologic (15 patients [65\%]).

In Table 5, we report selected PK parameters of AIC in each of the 15 patients included in the PK analysis and the associated percent changes in hematologic parameters (i.e. platelet, leukocyte, and neutrophil levels). It can be seen that four patients (reference numbers 01, 06, 11, and 14) with grade 4 platelets and grade $3 / 4$ neutrophils showed an increase in $C_{\max }$ and $\mathrm{AUC}(0-\mathrm{inf})$ of $\mathrm{AIC}$ on concomitant sorafenib administration. However, we also see an increased incidence of hematologic toxicities without an associated increase in the $C_{\max }$ and $\mathrm{AUC}(0-\mathrm{inf})$ on concomitant administration of sorafenib (patients with reference numbers 12 and 13) as well as an increase in $C_{\max }$ and AUC(0-inf) without an associated increase in hematologic toxicities (patient with reference number 09).

\section{Discussion}

In this paper, we report PK and safety data from the combination of sorafenib and dacarbazine in patients with advanced solid tumors. Our results indicate that while concomitant administration of sorafenib and dacarbazine decreased dacarbazine exposure, it resulted in increased AIC exposure. We also found that increased AIC exposure might be associated with an increased incidence of hematologic toxicities, likely because of the interference of methane diazohydroxide with erythropoiesis [22-24]. However, because of the small sample size, no statistically significant 
correlations between increased AIC exposure and hematologic toxicities could be established. Because of the study design, we could obtain PK profiles of sorafenib and its metabolites only in the presence of dacarbazine. Similar to other studies, we found that the PK parameters of sorafenib and its metabolites showed a high degree of variability [25]. Our data also show that sorafenib contributes approximately $83 \%$ to the sum of $\mathrm{AUC}(0-12)_{\mathrm{ss}}$ values, while the metabolites contribute approximately 9\% (M2), 4\% (M4), and 3\% (M5). This is comparable with data obtained from previous single-agent studies (data on file, Bayer HealthCare AG).

The combination of sorafenib and dacarbazine was associated with a clinically acceptable toxicity profile, with the vast majority of the grades $3 / 4 \mathrm{AEs}$ improving or resolving upon transient discontinuation and/or dose reduction of the study drugs. No unexpected serious adverse reactions were reported. The sorafenib-dacarbazine combination has also been investigated in randomized [14] and open-label [26] phase II studies, and in another phase I study [19] with similar safety results. Currently, the combination is being investigated in a phase II trial for sarcoma (Clinicaltrials.gov identifier: NCT00837148).

In conclusion, the combined treatment with sorafenib and dacarbazine may result in an increased exposure to AIC, which may be considered an indicator for the exposure to the active alkylating agent methane diazohydroxide. Due to the small number of patients in the present study, a statistically significant correlation between AIC exposure and observed hematologic toxicities, even if present, could not be established. Further studies may be necessary to more clearly characterize this potential drug-drug interaction.

Acknowledgments This study was sponsored by Bayer HealthCare AG, Leverkusen, Germany. We acknowledge the medical writing assistance provided by Meenakshi Subramanian, PhD, Evidence Scientific Solutions, which was supported by Bayer HealthCare AG and Onyx Pharmaceuticals, Inc.

Open Access This article is distributed under the terms of the Creative Commons Attribution Noncommercial License which permits any noncommercial use, distribution, and reproduction in any medium, provided the original author(s) and source are credited.

\section{References}

1. Wilhelm SM, Adnane L, Newell P, Villanueva A, Llovet JM, Lynch M (2008) Preclinical overview of sorafenib, a multikinase inhibitor that targets both Raf and VEGF and PDGF receptor tyrosine kinase signaling. Mol Cancer Ther 7:3129-3140

2. Wilhelm SM, Carter C, Tang L, Wilkie D, McNabola A, Rong H, Chen C, Zhang X, Vincent P, McHugh M, Cao Y, Shujath J, Gawlak S, Eveleigh D, Rowley B, Liu L, Adnane L, Lynch M, Auclair D, Taylor I, Gedrich R, Voznesensky A, Riedl B, Post LE, Bollag G, Trail PA (2004) BAY 43-9006 exhibits broad spectrum oral antitumor activity and targets the RAF/MEK/ERK pathway and receptor tyrosine kinases involved in tumor progression and angiogenesis. Cancer Res 64:7099-7109

3. Duran I, Hotte SJ, Hirte H, Chen EX, MacLean M, Turner S, Duan L, Pond GR, Lathia C, Walsh S, Wright JJ, Dancey J, Siu LL (2007) Phase I targeted combination trial of sorafenib and erlotinib in patients with advanced solid tumors. Clin Cancer Res 13:48494857

4. Kupsch P, Henning BF, Passarge K, Richly H, Wiesemann K, Hilger RA, Scheulen ME, Christensen O, Brendel E, Schwartz B, Hofstra E, Voigtmann R, Seeber S, Strumberg D (2005) Results of a phase I trial of sorafenib (BAY 43-9006) in combination with oxaliplatin in patients with refractory solid tumors, including colorectal cancer. Clin Colorectal Cancer 5:188-196

5. Mross K, Steinbild S, Baas F, Gmehling D, Radtke M, Voliotis D, Brendel E, Christensen O, Unger C (2007) Results from an in vitro and a clinical/pharmacological phase I study with the combination irinotecan and sorafenib. Eur J Cancer 43:55-63

6. Richly H, Henning BF, Kupsch P, Passarge K, Grubert M, Hilger RA, Christensen O, Brendel E, Schwartz B, Ludwig M, Flashar C, Voigtmann R, Scheulen ME, Seeber S, Strumberg D (2006) Results of a phase I trial of sorafenib (BAY 43-9006) in combination with doxorubicin in patients with refractory solid tumors. Ann Oncol 17:866-873

7. Siu LL, Awada A, Takimoto CH, Piccart M, Schwartz B, Giannaris T, Lathia C, Petrenciuc O, Moore MJ (2006) Phase I trial of sorafenib and gemcitabine in advanced solid tumors with an expanded cohort in advanced pancreatic cancer. Clin Cancer Res 12:144-151

8. Ryan CW, Goldman BH, Lara PN Jr, Mack PC, Beer TM, Tangen CM, Lemmon D, Pan CX, Drabkin HA, Crawford ED (2007) Sorafenib with interferon alfa- $2 b$ as first-line treatment of advanced renal carcinoma: a phase II study of the Southwest Oncology Group. J Clin Oncol 25:3296-3301

9. Gollob JA, Rathmell WK, Richmond TM, Marino CB, Miller EK, Grigson G, Watkins C, Gu L, Peterson BL, Wright JJ (2007) Phase II trial of sorafenib plus interferon alfa- $2 b$ as first- or second-line therapy in patients with metastatic renal cell cancer. J Clin Oncol 25:3288-3295

10. Escudier B, Lassau N, Angevin E, Soria JC, Chami L, Lamuraglia M, Zafarana E, Landreau V, Schwartz B, Brendel E, Armand JP, Robert C (2007) Phase I trial of sorafenib in combination with IFN alpha-2a in patients with unresectable and/or metastatic renal cell carcinoma or malignant melanoma. Clin Cancer Res 13:18011809

11. Adjei AA, Molina JR, Mandrekar SJ, Marks R, Reid JR, Croghan G, Hanson LJ, Jett JR, Xia C, Lathia C, Simantov R (2007) Phase I trial of sorafenib in combination with gefitinib in patients with refractory or recurrent non-small cell lung cancer. Clin Cancer Res 13:2684-2691

12. Gridelli C, Rossi A, Mongillo F, Bareschino M, Maione P, Ciardiello F (2007) A randomized phase II study of sorafenib/gemcitabine or sorafenib/erlotinib for advanced non-small-cell lung cancer in elderly patients or patients with a performance status of 2: treatment rationale and protocol dynamics. Clin Lung Cancer 8:396-398

13. Agarwala SS, Keilholz U, Hogg D, Robert C, Hersey P, Eggermont A, Grabbe S, Gonzalez R, Patel K, Hauschild A (2007) Randomized phase III study of paclitaxel plus carboplatin with or without sorafenib as second-line treatment in patients with advanced melanoma [abstract]. J Clin Oncol ASCO Annual Meeting Proceedings Part I. (June 20 Supplement) 25:8510

14. McDermott DF, Sosman JA, Gonzalez R, Hodi FS, Linette GP, Richards J, Jakub JW, Beeram M, Tarantolo S, Agarwala S, Frenette G, Puzanov I, Cranmer L, Lewis K, Kirkwood J, White JM, Xia C, Patel K, Hersh E (2008) Double-blind randomized phase II 
study of the combination of sorafenib and dacarbazine in patients with advanced melanoma: a report from the 11715 Study Group. J Clin Oncol 26:2178-2185

15. Azad NS, Posadas EM, Kwitkowski VE, Steinberg SM, Jain L, Annunziata CM, Minasian L, Sarosy G, Kotz HL, Premkumar A, Cao L, McNally D, Chow C, Chen HX, Wright JJ, Figg WD, Kohn EC (2008) Combination targeted therapy with sorafenib and bevacizumab results in enhanced toxicity and antitumor activity. J Clin Oncol 26:3709-3714

16. Richly H, Kupsch P, Passage K, Grubert M, Hilger RA, Voigtmann R, Schwartz B, Brendel E, Christensen O, Haase CG, Strumberg D (2004) Results of a phase I trial of BAY 43-9006 in combination with doxorubicin in patients with primary hepatic cancer. Int J Clin Pharmacol Ther 42:650-651

17. Reid JM, Kuffel MJ, Miller JK, Rios R, Ames MM (1999) Metabolic activation of dacarbazine by human cytochromes P450: the role of CYP1A1, CYP1A2, and CYP2E1. Clin Cancer Res 5:2192-2197

18. Lathia C, Lettieri J, Cihon F, Gallentine M, Radtke M, Sundaresan P (2006) Lack of effect of ketoconazole-mediated CYP3A inhibition on sorafenib clinical pharmacokinetics. Cancer Chemother Pharmacol 57:685-692

19. Eisen T, Ahmad T, Gore ME, Marais R, Gibbens I, James MG, Schwartz B, Bergamini L (2005) Phase I trial of BAY 43-9006 (sorafenib) combined with dacarbazine (DTIC) in metastatic melanoma patients [abstract]. J Clin Oncol ASCO Annual Meeting Proceedings Part I. (June 1 Supplement) 23:7508

20. Soria J, Lazar V, Lassau N, Pena C, Massard C, Robert C, Koscielny S, Deutsch E, Zafarana E, Armand JP (2007) Sorafenib (S) and dacarbazine (D) combination in patients (pts) with advanced malignant solid tumors: phase I study with tumor biopsy genomic analysis and dynamic contrast enhanced ultrasonography (DCEUS) [abstract]. J Clin Oncol ASCO Annual Meeting Proceedings Part I. (June 20 Supplement) 25:3556
21. Therasse P, Arbuck SG, Eisenhauer EA, Wanders J, Kaplan RS, Rubinstein L, Verweij J, Van Glabbeke M, van Oosterom AT, Christian MC, Gwyther SG (2000) New guidelines to evaluate the response to treatment in solid tumors. European Organization for Research and Treatment of Cancer, National Cancer Institute of the United States, National Cancer Institute of Canada. J Natl Cancer Inst 92:205-216

22. Ahmann DL, Bisel HF, Edmonson JH, Hahn RG, Eagan RT, O'Connell MJ, Frytak S (1976) Clinical comparison of adriamycin and a combination of methyl-CCNU and imidazole carboxamide in disseminated malignant melanoma. Clin Pharmacol Ther 19:821-824

23. Gutterman JU, Mavligit G, Gottlieb JA, Burgess MA, McBride CE, Einhorn L, Freireich EJ, Hersh EM (1974) Chemoimmunotherapy of disseminated malignant melanoma with dimethyl triazeno imidazole carboxamide and bacillus calmette-guerin. N Engl J Med 291:592-597

24. Costanza ME, Nathanson L, Schoenfeld D, Wolter J, Colsky J, Regelson W, Cunningham T, Sedransk N (1977) Results with methyl-CCNU and DTIC in metastatic melanoma. Cancer 40:1010-1015

25. Strumberg D, Clark JW, Awada A, Moore MJ, Richly H, Hendlisz A, Hirte HW, Eder JP, Lenz HJ, Schwartz B (2007) Safety, pharmacokinetics, and preliminary antitumor activity of sorafenib: a review of four phase I trials in patients with advanced refractory solid tumors. Oncologist 12:426-437

26. Eisen T, Marais R, Affolter A, Lorigan P, Ottensmeier C, Robert C, Corrie P, Chevreau C, Erlandsson F, Gore M, investigators Fts (2007) An open-label phase II study of sorafenib and dacarbazine as first-line therapy in patients with advanced melanoma [abstract]. J Clin Oncol ASCO Annual Meeting Proceedings Part I. (June 20 Supplement) 25:8529 